TITLE:

\title{
Reflexivity of Routines: An Ethnomethodological Investigation of Initial Service Encounters at Sushi Bars in Tokyo
}

\section{$\operatorname{AUTHOR}(\mathrm{S}):$}

Yamauchi, Yutaka; Hiramoto, Takeshi

\section{CITATION:}

Yamauchi, Yutaka ...[et al]. Reflexivity of Routines: An Ethnomethodological Investigation of Initial Service Encounters at Sushi Bars in Tokyo. Organization Studies 2016, 37(10): 1473-1499

ISSUE DATE:

2016-10-01

URL:

http://hdl.handle.net/2433/234984

\section{RIGHT:}

[Yutaka Yamauchi, Takeshi Hiramoto. Reflexivity of Routines: An Ethnomethodological Investigation of Initial Service Encounters at Sushi Bars in Tokyo. Organization Studies (Volume: 37 issue: 10, page(s): 1473-1499)] Copyright @ The Author(s) 2016. DOI: 10.1177/0170840616634125; この論文は出版社版でありません。引用の際には出版社版をご確認 ご利用ください。;This is not the published version. Please cite only the published version. 


\title{
Reflexivity of routines: An ethnomethodological investigation of initial service encounters at sushi bars in Tokyo
}

\begin{abstract}
[141 words]
This study reconsiders the meaning and implications of reflexivity for the theory of routines. Due to their mundane nature, routines tend to be considered unambiguous phenomena that everyone can readily understand. The performative theory of routines has challenged this view by suggesting there is no guarantee that participants have the same understanding of a routine. Nonetheless, this theory has yet to explain how routines are possible in relation to divergent understandings. Through empirical analyses of customer-provider interactions videotaped at sushi bars, this study shows how participants themselves exhibit and use their understandings of routines within the routine performance. That is to say, understandings of a routine are reflexive part of the routine performance. It is not necessary to assume that divergent understandings are reconciled prior to the routine performance. Reflexivity helps clarify how routines are possible without a priori shared understanding.
\end{abstract}

\section{Keywords}

Ethnomethodology, reflexivity, routines, customer interactions 


\section{Introduction}

This study asks how a routine can be performed when participants have varied understandings of the routine. In examining this question, the current study aims to build upon the performative theory of routines as advanced by Feldman and Pentland (Feldman, 2000; Feldman \& Pentland, 2003; Pentland, Feldman, Becker, \& Liu, 2012; Pentland, Haerem, \& Hillison, 2011) by examining individuals' own reflexive understandings of routines. Specifically, as opposed to imposing researchers' definitions of routines, the present research draws on the ethnomethodological notion of reflexivity in which an individual's own understanding of a routine is presented and used to organize the activities as a routine (Garfinkel, 1967). To this end, the current study focuses on high-end services, where customers often do not fully understand service routines but nonetheless achieve expected routines such as ordering dishes and drinks. This type of engagement with service routines is examined in detail through empirical analysis of customer interactions at traditional sushi bars in Tokyo.

Many companies, particularly those in high-grade market categories, try to present their products and services to the customers as something beyond what most people typically experience in their daily lives. For instance, many restaurants offer sophisticated services that are quite far from those experienced by customers on an everyday basis. Additionally, in these establishments the physical environment is designed to be nonquotidian, and menus include esoteric food and drink, much of which may be unfamiliar to customers. The service staff behaves professionally, and the common response among customers is to try to live up to a sophisticated standard set by the providers. When going to an upscale restaurant, a person often worries about such things as how to dress, what to order, and how to demonstrate proper etiquette while dining. Unless customers have extensive experience in these establishments, they are often faced with services they do not completely understand and struggle to master the service interactions.

Nonetheless, such interactions are largely routinized. High-end restaurants do not make an explicit claim that their services are difficult. Rather, they present customers a menu with esoteric dishes and a long list of rare wines, which are all treated as a routine part of the restaurant's service. Therefore, in high-end services, participants do not share the same understanding of the routine. Although customers may not be completely familiar with a routine in high-end service settings, they still perform the routine interaction by conveying their orders.

This study addresses the question of how a routine is achieved in relation to the divergent understandings of the routine various participants exhibit, and it challenges the assumption that different understandings of a routine need to be reconciled, or at the least sustained, for the routine to be achieved. An important element in 
explaining this phenomenon is the ethnomethodological notion of reflexivity (Garfinkel, 1967). That is to say, we need to examine how participants themselves present and use their own understandings of a routine within the performance of the routine. By reflexivity, we follow Garfinkel (1967) in viewing the understanding of an action as something produced, presented and observed as part of that action. When an action is produced, the action is made accountable; that is to say, the action is taken at a specific time in a specific situation so that others can observe, understand, and account for it. The understanding of this action is not separated from the action, e.g., through retrospective sensemaking or based on prior shared schemata. Through empirical analysis, we will reveal that participants themselves present and use different understandings of a routine reflexively within the performance of the routine.

To investigate this issue empirically, we chose to examine interactions at traditional sushi bars in Tokyo. This setting was chosen for two important reasons. First, traditional sushi bars are considered culturally esoteric. As in restaurants serving high French cuisine, sushi bars have various manners and jargon that customers are expected to master, but most barely manage to do this. Creating more difficulty for inexperienced patrons is the fact that at traditional sushi bars no written menu is provided and little hint is given as to what food and drink are available; moreover, prices are not indicated. Thus, customers are expected to know what fish is in season, what alcohol is an appropriate match for which dishes, what prices are appropriate for various items, and the like. Second, at sushi bars customers typically convey orders for individual items to the chef; that is, customers and chefs interact directly, whereas in typical restaurants chefs are separated from customers by a kitchen wall. In research for the current paper, several camcorders were placed in fixed positions at three high-end sushi bars; this arrangement gave us a unique opportunity to collect and analyze a rich set of interactions. By analyzing actual videotaped interactions recorded at sushi bars, we can reveal how routines can be achieved despite the varied understandings among participants.

Customer interaction is a particularly relevant area for investigating routines. Creating and changing a routine that involves customers is challenging (Turner \& Rindova, 2012). Feldman (2000), Feldman and Pentland (2003), and Pentland and Feldman (2007) have all examined routines at the organizational boundary, where an organization comes into contact with external parties, e.g., moving students into residence halls, academic hiring, and buying airplane tickets. Routines are important at these boundaries because there exists uncertainty as to how persons who are not familiar with each other carry out routines. It is within this context of previous research that the current study situates a specific examination of customer interactions as routines. 


\section{Reflexive Routine Performance}

\section{The Performative View of Routines}

The present study investigates how individuals present their understandings of a routine and negotiate with others to achieve performance in particular routines. This inquiry is in line with the recent performative view of routines in which theorists have offered a nuanced view that routines are flexible as well as stable (Becker, 2005; Cohen, 2007; Feldman \& Pentland, 2003; Nelson \& Winter, 1985; Tsoukas \& Chia, 2002).

Theories on routines have emphasized that they are in fact quite variable and flexible. Nelson and Winter (1985) pointed out that routines include activities that are not only smooth and predictable but also innovative. To explain the flexible aspect of routines, theorists have emphasized that routines refer not to resulting behavioral patterns but to their cause, i.e., the dispositions (Hodgson, 2008; Knudsen, 2008). While the behavior is rigid, dispositions are generative mechanisms that produce behaviors in a variety of situations. The pragmatist concept of habit helps show that our habitual actions are not necessarily repetitive or automatic but thoughtful and emotional (Cohen, 2007; Hodgson, 2013).

In line with this research, Feldman and Pentland presented a nuanced view of routines by distinguishing the ostensive and performative aspects of routine (Feldman, 2000; Feldman \& Pentland, 2003; Pentland et al., 2012; Pentland \& Feldman, 2008). This distinction is borrowed from Latour (1986), who claimed that the society is not ostensively defined by "the sociologist who attempts to stand outside it" (p. 264) but "performed through everyone's effort to define it” (p. 273). In other words, as opposed to the ostensive definition scholars give to a society, we need to observe and explain how participants themselves perform the activities and thereby exhibit their own definitions of the society. Drawing on this view, Feldman and Pentland (2003) described the ostensive aspect of a routine as referring to an abstract idea about the routine and the performative aspect as indicating situated actions of performing the routine. While routines can be viewed as static if we only focus on abstract ideas that people have about them, the dynamic aspects become apparent if we examine the actual performances of these routines in concrete situations. Much variation can be seen in performance because situations inevitably differ, and those who participate in these actions need to assess and adapt to current circumstances. The ostensive aspect of a routine helps people to guide, account for, and refer to specific performances of routines, while the performative aspect helps people to create, maintain, and modify the ostensive aspect. It is through this interplay of ostensive and performative aspects that routines can be achieved in each varied situation. 
Feldman and Pentland (2003) emphasized that there can be multiple, different ostensive understandings of a routine: "It is tempting to conceptualize the ostensive aspect of the routine as a single, unified object, like a standard operating procedure. This would be a mistake, because the ostensive incorporates the subjective understandings of diverse participants" (p. 101). To make this aspect more explicit, Pentland and Feldman (2008) specifically stated that plural use of 'ostensive aspects' was meant to emphasize the variety of understandings. Therefore, "The ostensive aspect of the routine gains in apparent objectivity and concreteness as the views of different participants come into alignment" (p. 101).

In a similar vein, Dionysiou and Tsoukas (2013) sought to explain how routine interaction is possible despite varied understandings of routines. They suggested that participants have "shared schemata" to induce compatible understandings as well as to address other elements of their understandings that may diverge. Because such divergent understandings are "peripheral" and "nonprototypical" compared to the shared "core" and "prototypical" understandings, routines can be achieved. Zbaracki and Bergen (2010) also touched on different understandings held by participants. Drawing on Nelson and Winter's (1985) notion of "routine as truce," they showed that participants can perform routines while these different understandings can be sustained under truce, and therefore little interaction is needed among participants. The present study also tackles this problem of different understandings of a routine exhibited by participants.

\section{A Problem with Ostensive Aspects of Routines}

It remains unclear how a routine is performed while different understandings of a routine are exhibited. Feldman and Pentland (2003), Dionysiou and Tsoukas (2013), and Zbaracki and Bergen (2010) use the notion of power to explain this negotiation. For instance, Feldman and Pentland write "Individuals or groups with power to identify particular performances as 'routine' have the power to turn exceptions into rules and, thus, to enact the organization in ways they think appropriate." (p. 110). Zbaracki and Bergen (2010) also suggest that once the truce collapses, a 'fight' ensues and forces participants to negotiate. However, this would indicate the fight to negotiate the routine is not actually part of the routine. The divergent understandings, if the difference is not too great, can be sustained without any 'fight' necessary within routine operations. Therefore these descriptions view negotiation as an activity separated from routine performance. It is assumed that once a routine is performed, the difference is already resolved or at least sustained.

Another solution to the problem of the varied understandings of routines is, as Dionysiou and Tsoukas (2013) suggested, to assume that while peripheral understandings differ, participants share some core understanding of a routine. That is to say, the difference is minimized to the periphery of a routine. However, by 
relying on what is shared a priori among participants and minimizing differences in understandings, this characterization undermines an important premise of the performative theory of routines vis-à-vis traditional routine theories: If we rely on what has already been shared prior to performance of a routine, the performance comes to be treated as simply an execution of what has been clearly shared. In this view we would need some prior activities, separated from the routine performance, that ensure the sharing of the core schemata. Although customers and providers do have large areas of shared understandings, such as shared language and commonsense knowledge, we need to inquire into how this difference in understandings is used in performance.

The arguments concerning routines in prior studies are based on the ambiguous relationship between the ostensive and performative aspects of a routine. While theorists have acknowledged that participants can have different ostensive understandings of a routine, there is no theoretical reason to choose one particular ostensive understanding over another. We cannot assume that multiple understandings are reconciled prior to routine performance — e.g., through power struggles—because in this case the routine performance itself has no basis for its routineness and must rely on a prior understanding, which would have been constructed in an activity separated from the routine. Furthermore, it cannot be presupposed that these understandings are reconciled after the routine performance because this means that the performance itself cannot be recognizable as a routine unless we rely on the retrospective account. We need to keep in mind, as Feldman and Pentland (2003) emphasize, that these two aspects together form the concept of routine. If we assume that there are separate and distinct activities, one to alter the ostensive aspect and another to perform a routine, the premise of the theory is undermined. Therefore, this ambiguity in the prior theory needs further elaboration.

In light of the above, we must view ostensive understanding as internal to performative actions. Therefore, the problem is to clearly describe how a routine performance itself can be organized and recognized as a routine by presenting and using the ostensive aspect in a performative manner. A theoretical approach that treats ostensive understandings as a reflexive part of performative actions is needed; ethnomethodology presents an appropriate approach for this purpose.

\section{An Ethnomethodological Perspective}

Ethnomethodology emphasizes that people do not take actions by blindly following rules; individuals present their own understandings of actions while taking situated actions (Gherardi \& Nicolini, 2002; Hindmarsh \& Pilnick, 2007; Llewellyn, 2008; Llewellyn \& Spence, 2009; Miettinen, Samra-Fredericks, \& Yanow, 2010; Suchman, 2007). When an individual produces an action, this person makes the action accountable without any explicit verbal description. By accountable, ethnomethodologists mean that the action 
is recognizable, understandable, and describable for others. Reflexivity refers to the fact that the account of an action is produced and observed within the action itself rather than the account being constructed elsewhere, e.g., before or after the action. Here it is helpful to look to a passage from Garfinkel (1967):

For the conduct of their everyday affairs, persons take for granted that what is said will be made out according to methods that the parties use to make out what they are saying for its clear, consistent, coherent, understandable, or planful character, i.e., as subject to some rule's jurisdiction-in a word, as rational. To see the "sense" of what is said is to accord to what was said its character "as a rule." "Shared agreement" refers to various social methods for accomplishing the member's recognition that something was said-according-to-a-rule and not the demonstrable matching of substantive matters. The appropriate image of a common understanding is therefore an operation rather than a common intersection of overlapping sets. (p. 30, emphasis in original)

Therefore, each of us needs to make each action accountable as something produced according to a certain rule. Simply assuming shared schemata, or "overlapping sets" in Garfinkel's terms, does not guarantee the achievement of an interaction.

In this view, routine is not defined outside the performance of actions. We make each of our actions accountable as part of a routine. To do so, we perform actions in a routine manner without having to verbally explain the routine. When a person states something as a matter-of-fact without a verbal explanation, this can be described as that person presenting an understanding that this utterance is a routine part of the situation. For example, when saying ' $\mathrm{Hi}$ ' as we meet somebody, we make sure that this utterance can be understood as part of a greeting routine. We do not say in advance that we are going to greet each other. Nor do we abruptly say, "Hi," in any given situation. We choose a correct time in relation to ongoing prior actions and judge the right distance, posture, eye gaze, and the like to make this action accountable as a greeting. Subsequently the individual we have greeted likely returns with a 'Hi' in a similarly accountable manner. By doing so, this person presents that s/he understood our initial utterance as a greeting routine. That is, we accomplish a routine greeting exchange through this reflexive process of presenting an understanding of the routine and acknowledging the presented understanding.

Applying this ethnomethodological perspective in the context of routine performativity, we claim that the ostensive aspect, i.e., the generalized idea about a routine, is a reflexive part of the performative aspect, i.e., situated performance. That is to say, an ostensive idea is presented, negotiated, and constructed through situated practice. Routines can be recognizable as routines, not because analysts impose certain criteria of routineness, 
but because participants themselves present their understanding of routineness and use this understanding to organize their actions as routines. Therefore, ostensive aspects are not simply brought to bear from outside a current situation to guide, account for, or refer to actions, but are themselves produced and presented reflexively within the actions that they guide, account for, or refer to.

A number of researchers have used ethnomethodology to examine customer interactions (Clark \& Pinch, 2010; Kuroshima, 2010; Lee, 2009; Llewellyn \& Hindmarsh, 2013; Moore, Whalen, \& Gathman, 2010; Mortensen \& Hazel, 2014; Pinch \& Clark, 1986). These studies reveal ways in which participants use subtle methods to achieve mutual orientation so that interactions can be smoothly achieved despite divergent understandings of a situation. For instance, Clark and Pinch (2010) have shown how customers and store employees start conversations (see also, Mortensen \& Hazel, 2014). Customers use various cues such as standing in front of a product for an extended period of time or holding a product in their hand, which then signals employees to approach the customers. Therefore, the action of speaking to a customer is made accountable in the context of prior actions taken by the customer as well as the employee. Lewellyn and Hindmarsh (2013) showed that service providers used subtle cues to make inferences, rather than to ask explicitly, as to whether customers are old enough for a senior discount, whether they qualify for a student discount, and which person is paying when customers are in a group. Customers actively take part in making the inferences possible through certain utterances and configuration of their bodies and objects. Through these inferential efforts, customers and providers perform routines delicately and smoothly without much disruption. Moore, Whalen, \& Hankinson (2010) showed how customers' requirements are translated into company routines embodied in standard forms, which are not sufficiently flexible to describe a wide range of customer requirements; the emphasis of their research was on the practices by which participants can "accommodate the insufficiencies of the standard form" (p. 186).

These ethnomethodological studies show that participants have their own ways to handle possible different understandings of the situation. Nonetheless, these studies tend to stress methods for aligning participants' understandings. As a result, little attention has been given to the ways in which participants present and use different understandings of a routine to define a situation. By defining a customer interaction routine in a certain manner, service providers can define their services, and in particular they may be able to demarcate the service they offer as something exceptional. Especially in this last situation, customers often do not understand and master completely the routines thus defined, and providers and customers have different ostensive ideas of 
the routine. This study examines this use of different understandings within routine performances. Accordingly, we argue that different understandings of a routine are part of the routine performance.

Therefore this study poses the following research question: How is a routine achieved despite the fact that participants exhibit disparate understandings of a routine? Only by explicating this process can we bring about the full potential of the theory of routine performativity. Prior studies have implied that this process exists, but it has yet to be elaborated.

\section{Method}

As noted above, sushi bars were chosen as locations to observe service encounters because at these restaurants the service is culturally rich and deep, and customers are expected have a high level of knowledge in order to engage in the service ${ }^{1}$. Many customers seem to have trouble understanding the routines at these establishments, although for the most part customers eventually manage to perform them. As we felt this situation was of particular interest to the study, we decided to focus more attention on ordinary customers who were not necessarily well experienced in dining at sushi bars. Nonetheless, we chose to recruit a few individuals who had a great deal of experience at these restaurants in order to examine contrasts in various interactions; in this case, we expected to see truly routine interactions in which little difference in understanding is presented. We believed such cases would help explicate how difference is presented in cases of less experienced customers. We asked each person how many times a year he or she went to high-end sushi bars such as the ones used in this study; some were highly experienced and called themselves sushi connoisseurs, or sushi-tsu in Japanese. We also tried to recruit a few customers who were regular patrons at these sushi bars.

Observations were made during evening operating hours at three sushi bars in Tokyo, which we will refer to as A, B and C. All three are prominent sushi bars and have been repeatedly featured in books and magazines. The typical bill for one person at these sushi bars ranged from 15,000 to 25,000 Japanese yen (roughly 125 to 210 USD). The meals lasted about two hours. We observed 11 customers, three chefs, and three assistants at A; six customers, two chefs, and one assistant at B; and seven customers, two chefs, and one

\footnotetext{
${ }^{1}$ Sushi bars are considered to embody unique culture. There is jargon and etiquette specific to sushi that customers are expected to master. The traditional sushi bars we studied tended to have the following features in common: the chefs are typically dour, serious, and austere, and customers are nervous eating in front of them. A good example of this can be seen in the recent documentary "Jiro Dreams of Sushi," when a well-known food writer states, "When I went to Jiro the first time, I was nervous. After going for years, I am still nervous." In fact, the same situation can be found in these types of sushi restaurants in America. Corson (2009) wrote, "Many Americans walk into a sushi restaurant and opt to sit at a table because they find the sushi bar intimidating. Sitting at a table feels familiar, as does ordering from a menu... Turning one's back on familiarity and choosing to sit at the sushi bar requires courage, but the experience is more interesting... Not knowing what to expect, either with the ingredients or the order in which they are served, is part of the fun...Americans can take solace in the knowledge that they are not alone. Many Japanese people also find the sushi bar intimidating" (p. 317). Nonetheless, there are a variety of casual sushi restaurants that provide customers with written menus just like other kinds of restaurants.
} 
assistant at C. Information on the customers who participated in the study is summarized in Table 1 . Some customers came to the restaurants in a group; others dined alone. We asked each participant to choose whether he or she would bring a companion, as we desired that the participants to try to simulate a typical case of their visiting a sushi bar.

Insert Table 1 about here.

We analyzed the actual social interactions through conversation analysis; this method is derived from and closely related to ethnomethodology, and it has been shown to offer unique insights into organizational phenomena (Llewellyn \& Hindmarsh, 2010; Miettinen et al., 2010). Interactions between chefs and customers were videotaped with multiple camcorders. As it was not feasible to videotape customers at establishments without permission, participants who agreed to the video recording were recruited for this study. We asked them to behave as naturally as possible while dining at the restaurant. Of course, filming might affect participant behavior; however, as long as the scope of research was limited to routines involving service interactions, participants would not have too much leeway to deviate from expected conduct in this type of interaction. Typically, once a person begins to interact with others, most attention is directed to the interaction. Therefore in this case, it was expected that the participants should not be able to direct much concentration to the video recording.

The first step of conversation analysis is to transcribe interactions word by word according to the conventions developed in conversation analysis research (see Appendix). The transcription system allows examination of conduct in detail. For instance, a number inside round parentheses indicates the length of a pause, and left and right brackets represent where an overlap of two or more utterances starts and ends.

Subsequently these transcriptions are extensively reviewed in order to arrive at a detailed analysis of the interactions. It is important to examine each individual instance of an interaction and ground the analysis in what is observable in the sequential data prior to comparing any individual instance with other data. The analysis of these interactions is based on how participants themselves understand actions, and these actions include both verbal and non-verbal conduct. Since ethnomethodology is grounded in the supposition that actions are accountable, a participant's understanding of each action can be observed in the action itself. In particular, whether a certain analysis is correct is ascertained by examining the subsequent responding action. That is, conversation analysis does not attach any theoretical importance to these actions in advance of their being performed. 
Accountability of actions is inevitably embedded within the in-situ context of conversation.

Ethnomethodologists suppose that each action of an interaction can only be understood when it is connected to a particular context at each moment in time. Such a context largely consists of prior actions and is renewed through actions. Some contextual information shared by all involved parties may be relevant, such as commonsense knowledge of the particular culture. Yet, the analysis needs to show how such contextual information is made relevant through actions. Therefore, contextual information that can affect the understanding of participant conduct will be examined during the analysis.

The following is an example and explanation of how actions are analyzed in conversation analysis as used in the current study.

\section{Fragment 1}

01 Chef: Drinks?=

02 AS : =How would [you like ${ }^{\circ}$ to do about drink ${ }^{\circ}$ ]

$03 \mathrm{Bla}$ : [Well shall we go for beer?] ((to Blb))

04 B1b : Yes

$05 \quad(0.2)$

06 Chef: [Yes]

07 Bla : [Wel]l beer:

08 Chef: $<$ Ye>s

$09 \quad($.

$10 \mathrm{Bla}:$ Yes

11 AS : Can I (.) bring a large bott [le

12 Bla : $\quad[\underline{A h}$ uh, be- (0.2) a large bottle

13 is ok[\#ay\#

14 AS : $\quad\left[{ }^{\circ}\right.$ Yes $^{\circ}$

Fragment 1 represents transcribed interaction between four parties — the chef (Chef), the assistant (AS), two customers (B1a, B1b). Each line corresponds to a sequential development of their talk and other conduct. In line 01 , the chef utters "Drinks" with a rising intonation. The equal sign immediately after this utterance and the beginning of the next line (line 02 ) indicates that there is no pause between these two points, while typically a brief pause is observed between turns. Note that the noun "Drinks" together with a rising intonation can be heard as a solicitation of an order. This is a typical instance of how conversation analysis is employed to describe a recognizable action taken by participants: It is recognizable as a solicitation of an order. This description of recognizable action should not be confused with a researcher's interpretation of participant conduct. Researchers using conversation analysis must use commonsense knowledge about how mundane actions are displayed by members of society and ground their analysis in observable detail of the data. In other words, saying "Drinks?" is an example of accountable action that is easily recognized by competent members of society; anybody can hear the chef's utterance as reasonable, natural conduct of order solicitation. Moreover, 
participants themselves understand the chef's utterance as a solicitation for an order, and this is obvious when we see how the participants respond to the chef's utterance. B1a is beginning to respond to chef's question in the midst of AS's utterance - as the customer responds with an order, he is observed to have understood the chef's action as order solicitation. As this analysis shows, conversation analysts examine how participants form recognizable action for other parties in interaction, and thereby make their conduct accountable.

Each service interaction started with drink orders, which were taken as soon as the customers were seated. We decided to focus on initial encounters, which included the first drink orders and then first food orders. These first interactions were the occasions where customers' understandings of the routine were the most uncertain because after a few rounds they became more familiar with the routine. As we analyzed the first food orders, we realized the analysis we conducted for the first drink orders was even more salient. Therefore, we focused on data collected from these initial food and drink orders and determined that presenting later ordering interactions did not add much to the analysis.

Although it is common for research using conversation analysis containing transcriptions of languages other than English to contain three lines (Roman letters, word-for-word translation, and English translation) for each utterance, this study uses a simplified version in which Roman letters and word-for-word translation are omitted. We have modified the word order of the English-translated utterances so that the nuance of the original Japanese word order can be captured. For this reason, the English translation might be unusual. We sought to balance faithful presentation of the original Japanese with an easily readable translation in these sections.

\section{Results}

The analysis in the following sections is presented in several stages. First, we provide a contextual description beginning with the customers' arrival and leading to the first ordering interactions. Then, we describe first how drink orders are achieved and second how the first food orders are achieved. We discovered that customer interactions, after a greeting, began with drink orders, which were the first occasion where customers' understandings were revealed. Subsequently similar patterns were observed in the first food orders.

In the analysis of drink orders, our first aim is to show that chefs through their conduct present their own understanding of routine at their sushi bars. To begin, we examine the form of a chef's question for the first drink order; here chefs pose their questions without giving customers many clues as to what is appropriate to order. Subsequently, the analysis revealed roughly three types of customer responses to the chefs' questions: customers provide simple answers, add rationales for their choices, or indicate that they have difficulty answering the questions. Customers often exhibit that they are uncertain as to how to answer the question 
properly. This sequential analysis demonstrates how chefs and customers present and negotiate their understandings of the routine. Chefs define the routine in a certain manner that customers may not completely understand and master. Lastly, the analysis of food order sequences also shows the customers often exhibit that they have trouble understanding the chefs' questions or that they understand the questions differently from the way expected by the chefs. Our point here is to demonstrate how a routine is achieved through detailed coordination of the chefs' and the customers' conduct despite their different understandings of the routine.

\section{From Entering the Sushi Bar to the First Drink Order}

When a customer enters a sushi bar, this person is guided to a seat in front of a chef. A typical scene is shown in Figure 1. Many sushi bars do not have tables for groups of customers. Instead, there is a long counter at which customers are seated facing the chefs. Typically two to three chefs are behind the counter and eight to 12 customers can be seated. This physical arrangement enables the customer to engage in face-to-face interactions with the chef. Sometimes prepared fish blocks are displayed in a glass case on top of the counter; sushi bars A and B had such displays while sushi bar C did not. Chefs face customers across the counter, whereas assistants come from behind the customers.

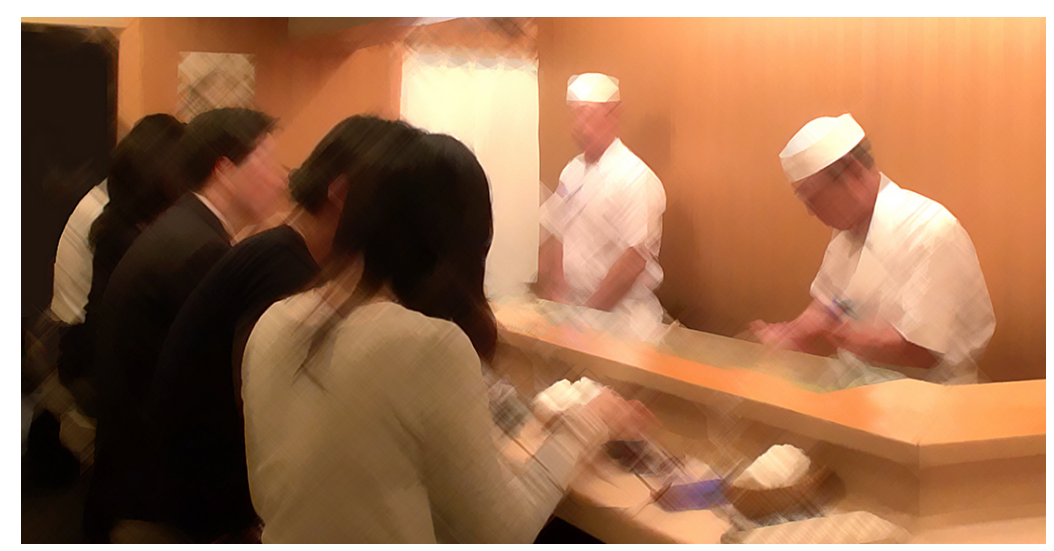

Figure 1: A sushi bar

Shortly after a customer is seated, the chef typically greets him or her. The greeting sequence contributes to initiating the face-to-face, one-to-one interaction between these persons (for a group of customers, one-togroup interaction). Sometimes, when speaking, through posture and gestures the chef shows his or her orientation toward the one-to-one nature of interaction, as shown in Figure 2. Here, the chef slightly bends his body forward and opens his arms when he presents a first question to the customer. Thereby, the chef creates a one-to-one interaction framework. 


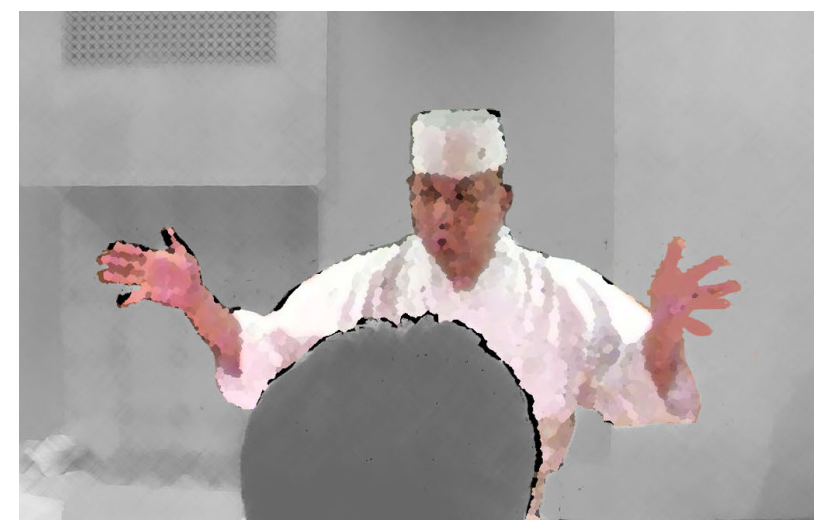

Figure 2: The chef speaking to a customer

\section{Simple Cases of Drink Order}

We first review simple examples of the drink order interactions. These are called simple because they are minimally organized - a provider asks a question and a customer answers - without various issues that will be discussed in subsequent examples (except in cases involving regular customers, which are even more straightforward). As in Fragment 1 above, Fragment 2 shows an example of soliciting an order once the engagement starts. This customer has come to this sushi bar for the first time. 'Chf2' indicates an assistant chef and AS an assistant (non-chef restaurant staff).

\section{Fragment 2}

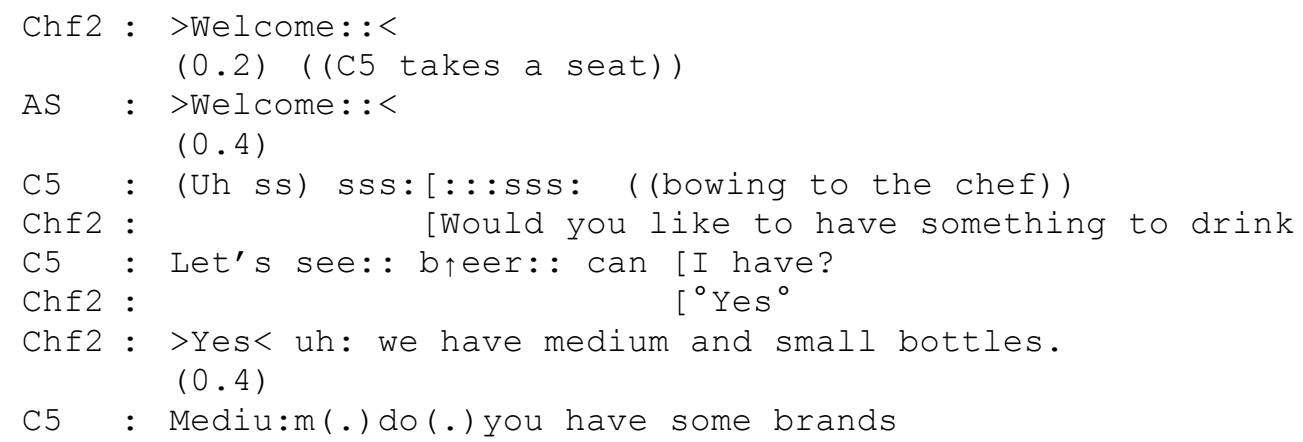

As soon as the customer and chef exchanged greetings (line 01-05), the chef said to the customer, 'Would you like to have something to drink?' at line 06 . This question is asked when the customers are provided with no explanation of the service and no written menu. This kind of question was observed recurrently in all three sushi bars. In the next turn, the customer managed to order beer in line 07 . Note that rather than simply stating his order, he draws out the vowel sounds in the word 'beer' with a higher and prolonged voice while looking at Chf2 - probing Chf2's reaction to his choice. Nonetheless, this interaction appears smooth overall. The next fragment shows a similar pattern.

\section{Fragment 3}


(.)

03 C3 : .hhhhh(0.3) The::n(.) Shall I get a glass of be [e::r

In this case, the chef's question in line 01 is quite brief. After some filler tokens ('the::n') and a pause, the customer answers naturally in line 03. In the next fragment, the assistant (AS) initiated the interaction.

\section{Fragment 4}

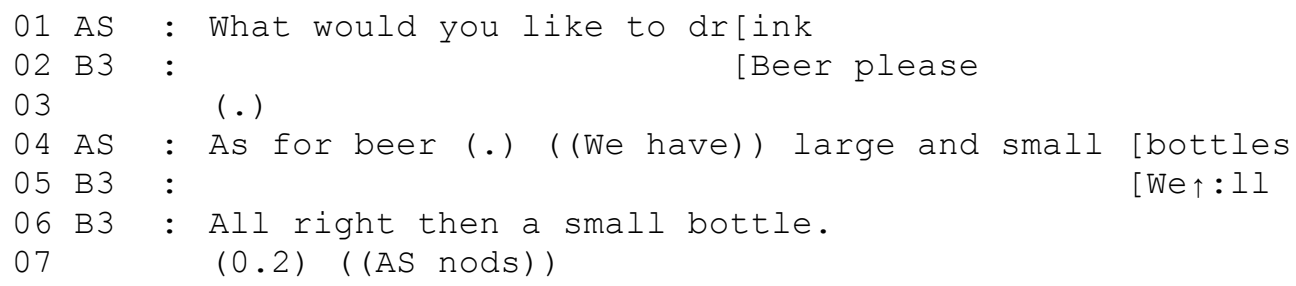

The question in line 01 was phrased slightly differently from the previous cases, but it was also asked as soon as the customers were seated and was not preceded with any other information. In this case, the customer responds with a concise answer, even overlapping with the assistant as if he had expected this question.

As these four fragments show, the solicitation of an order takes the same form. It is standardized that customers enter the premise, are guided to seats, exchange greetings, and receive a question to solicit an order. Note that this type of standardized question is understandable as defining a routine since it presupposes that customers can respond to it without any further information. The chefs do not provide any clue about menu items, prices, or other contextual information. In other words, chefs exhibit their understanding that the concise question is enough for customers to order a drink, and that customers would know that they are expected to be able to order a drink. Therefore, to define a routine, the providers simply perform their actions in a concise and matter-of-fact way without explanation. In this sense, the participants' own understanding of the routine is exhibited reflexively within the performance of the routine.

All customers in Fragments 1 to 4 could respond to the chef's initial question without much difficulty. Therefore, the customers in these fragments exhibited understandings of the routine that were not markedly different from the understandings exhibited by the chefs. Nonetheless, this question is difficult for many customers to answer. Next, we will analyze how customers respond to these questions and show that customers 
and providers are both oriented to the difficulty of these questions ('orient to' the difficulty in this context refers to the fact that the participants understand the difficulty and produce their actions based on that understanding).

\section{Giving an Account}

In Fragment 5, a chef approaches a just seated customer and greets the customer by saying, 'Welcome,' and then the customer returns a greeting. The chef asks the customer a question almost identical to those in the other fragments.

\section{Fragment 5}

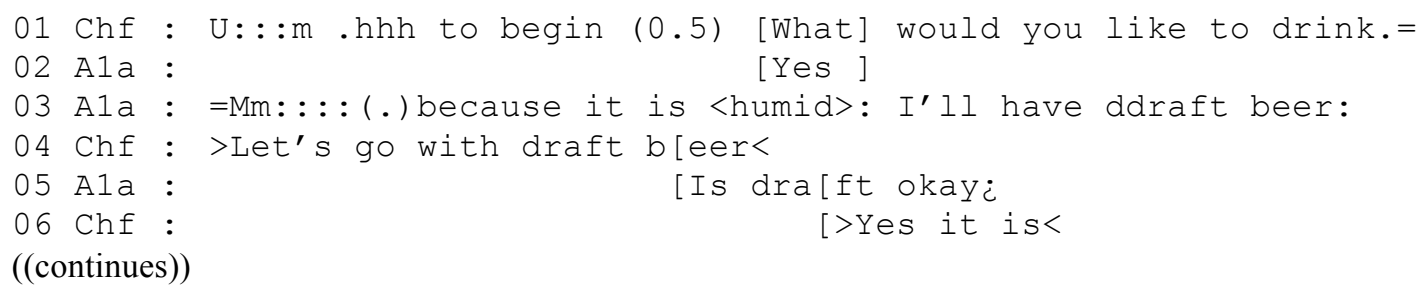

Note that this question in line 01 is constructed as a first utterance of a question-answer adjacency pair sequence (Schegloff, 2007). That is to say, an answer is normatively expected after this question. The chef's utterance in line 01 is syntactically, prosodically, and pragmatically complete, thus chef's turn is seen to be finished at this point. The customer is required to respond with an answer in next turn. A straightforward response could simply be given such as 'a beer please' or 'tea' as we saw in previous fragments. Note that in this fragment, these customers had never been to this sushi bar before; nor had they been given a written menu. Moreover, no menu information was posted on the wall or was otherwise visible. These customers were not even informed of the way in which service was organized at this establishment; what kind of food will come, in what order, and so on.

Through this question, the chef defined the type of person his customer should be: somebody knowledgeable and experienced enough to respond to this question without any problem. He also defined the sushi bar as a certain type of establishment: a restaurant that asks customers to behave as knowledgeable and experienced patrons. The question was recognizable as part of a routine task not only because it was embedded within the flow of actions associated with the mundane beginning phase of a consumer experience, but also because it was asked as a matter of course without any explanation of its occurrence. Thus, we can say that the question was designedly and recognizably uttered as a routine. The chef's understanding of the routine was reflexively presented within his performance.

Given that the chef's question was constructed to define the nature of the service, the customer's response can be seen as an answer to the definition. Evidence for this observation is seen in the response (order) 
and the subsequent receipt for the order by the chef. Mostly customers simply ordered a drink using a sentence or noun phase (Fragments 1-4). On the other hand, we can see a slightly different phenomenon in Fragment 5. In this case, the customer managed to answer in line 03 . Note that he prolonged the sound of the word for 'beer.' He was heard to be probing how the chef would respond while indicating his choice, beer (this was also observed in Fragment 2). He could not complete his order specification without some kind of reaction from the chef. Therefore, he was heard to be unsure about his choice. Note also that the customer prefaced the order with a rationale for his choice: 'because it is humid.' This also shows his uncertainty about the order: A rationale is required to present his choice. In sum, this customer exhibits that he does not understand the routine in the same way as the chef, and this understanding is reflexively exhibited within the customer's performance.

In turn, the way the chef received the order shows his understanding that the order is provided as an answer to a difficult question. The chef accepted the order with a rather emphatic utterance in line 04 . This 'Let's' utterance has 'we' as its subject. That is to say, he involved himself in the response and thus demonstrated his agreement with the customer's order. This kind of emphatic action would have been awkward unless it had been required by the situation (For example, we don't hear "Let's go with a Big Mac" at McDonald's). In this manner, he validated the customer's choice as appropriate.

We can summarize the analysis thus far in that the chefs posed the initial questions as a matter of fact and thereby presented their own understanding regarding the nature of the service routine at their restaurants. Some customers could not completely understand and master the definition and showed their uncertainty. Other customers were able to assess the chefs' understanding and managed to answer the initial questions.

\section{Assistance Offered by the Providers}

Customers sometimes exhibited difficulty in answering the providers' questions. In such cases, the providers offered assistance by giving some hints. Dots in parentheses (.....) indicate that an utterance was inaudible.

\section{Fragment 6}

01 Chef: What would you like to drink

$02 \quad(0.5)$

$03 \mathrm{A3a}:$ We::11 uh::m (1.2) (......)[ do you have

04 Chef: 05 A3a : ${ }^{\circ}:^{\circ}=$

06 Chef: =sake,

$07 \mathrm{A3a}$ : Yes.

08 Chef: U:m shochu.

$09 \quad(0.4)$

$10 \mathrm{A3a}:{ }^{\circ} \mathrm{hum}^{\circ}=$

11 Chef: =a glass of (0.3) white wine or, champagne ${ }^{\circ}$ [or something ${ }^{\circ}$

$12 \mathrm{~A} 3 \mathrm{a}$ :

${ }^{\circ}{ }^{\circ}=$
$=$ a glass of

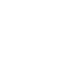

[huh: 


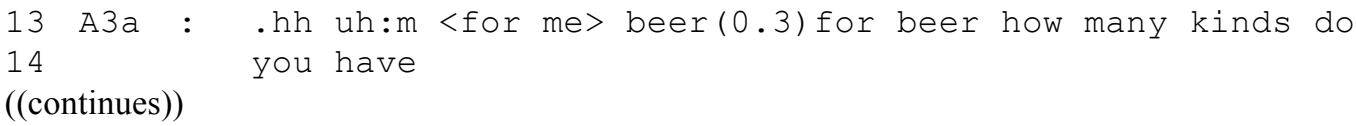

In this case the customer does not respond to the chef's question and instead, in line 03, shows his hesitation to order by using various resources. First, there is a 0.5 second gap between the chef's question and his response (line 02). After this gap, the customer utters prolonged filler ("We::1l uh::m") and looks right and then left as if searching for some information, e.g., a menu on the wall, as shown in Figure 3. This observation that he is searching for information about the menu is confirmed by the following utterance. Although the utterance is partly inaudible, it is certain that he asks the chef what kind of drinks he can choose. The chef's response to this was to list items such as "beer" (line 04) and "sake" (line 06) so that the customer could choose a drink from the list. This timely assistance exhibits the chef's understanding of the customer's behavior as expressing difficulty with ordering. In sum, the customer exhibited his own understanding of the routine, which diverged from the understanding the chef exhibited. In turn, the chef then exhibited his understanding of the customer's understanding, i.e., of the difference in understandings between them, by his subsequent actions.

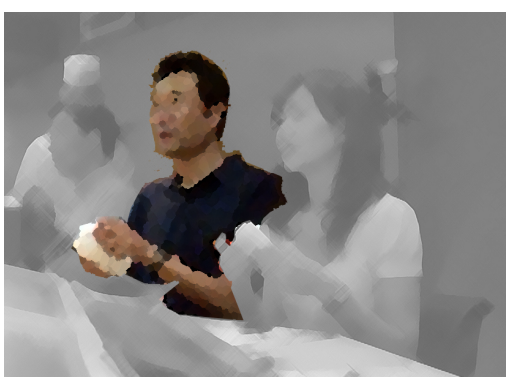

1. Looking at the chef

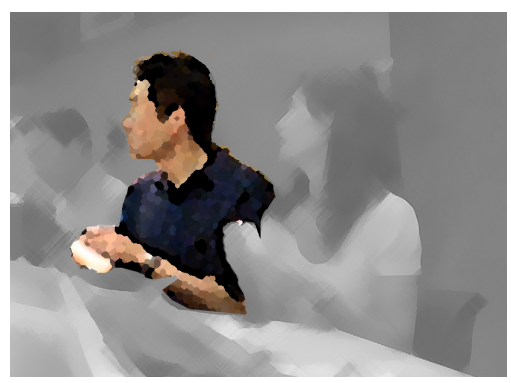

2. Looking right

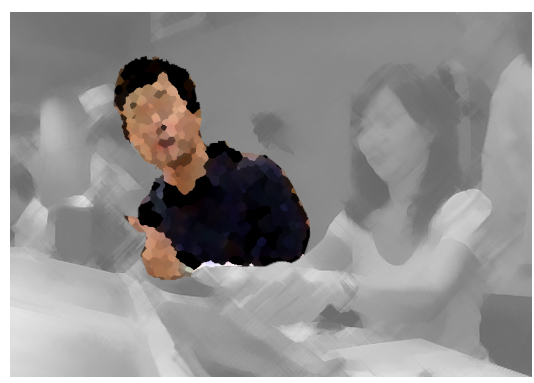

3. Looking left

Figure 3: A customer looking right and left

We can examine a similar example in the following fragment with a group of three customers.

\section{Fragment 7}

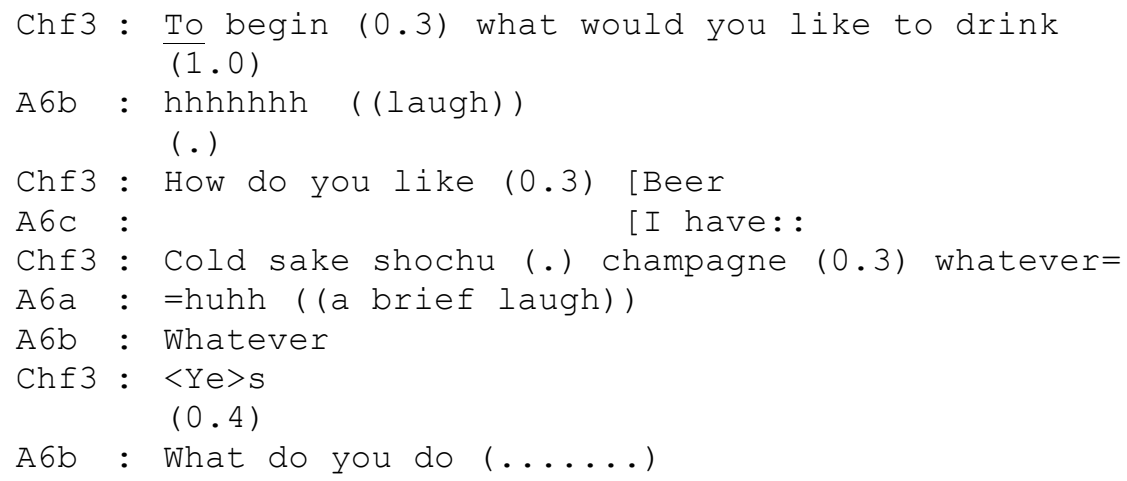




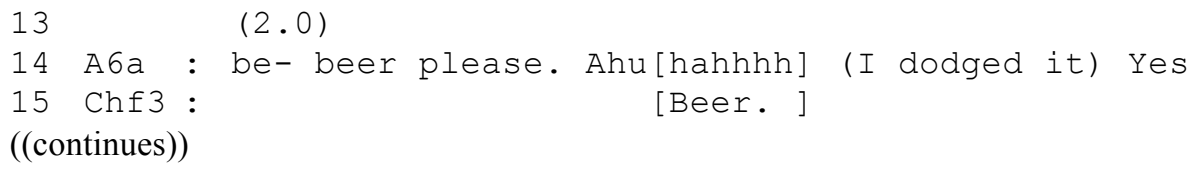

The customer in this fragment starts laughing (line 03) in response to the chef's question after a long pause in line 02 . Note that her laughing is constructed as a response to the chef's question; it is located at a position immediately following the question. Moreover, she looks directly at the chef while laughing. By laughing as a response to the question, the customer shows the difficulty in answering the question. Seeing this response, the chef lists some drinks to choose from-overlapping another customer who tried to respond (line 06). The chef adds 'whatever' to this list (line 07) and one of the customers responds to this comment with a brief laugh (line 08). Another customer repeats, 'whatever.' This 'whatever' leaves customers with the responsibility to choose, but these customers do not seem to be able to do so. As soon as one of the customers stammeringly ordered beer, he laughed (line 14). Although what the customer is saying following his laughter is unclear, he appears to formulate his situation as having faced a challenge by explicitly saying 'I dodged it.' All these utterances indicate that the customers found it laughable, or at least slightly embarrassing, that they could not respond smoothly to the chef's question. In this case, therefore, the difficulty of the chef's question is made explicit.

These cases show that the customers have trouble answering the chefs' initial questions, which were presented as a matter of fact. By indicating difficulty answering these questions, customers presented a marked divergence from the chef's definition of the routine. The chefs then gave a list of possible items to choose from, thereby making ordering easier for customers. It should be noted that the chefs did not do this to help customers until the customers showed uncertainty with answering the initial questions.

\section{A Regular Customer's Case}

Thus far, we have seen cases where customers exhibited the uncertainty they faced in responding to the chefs' questions. These customers could not perform the routine in the manner that the chefs' definition presupposed. On the other hand, some customers were accustomed to these types of routines and thus oriented to demonstrating their experience or validating their status as regulars. Fragment 8 represents one instance.

\section{Fragment 8}

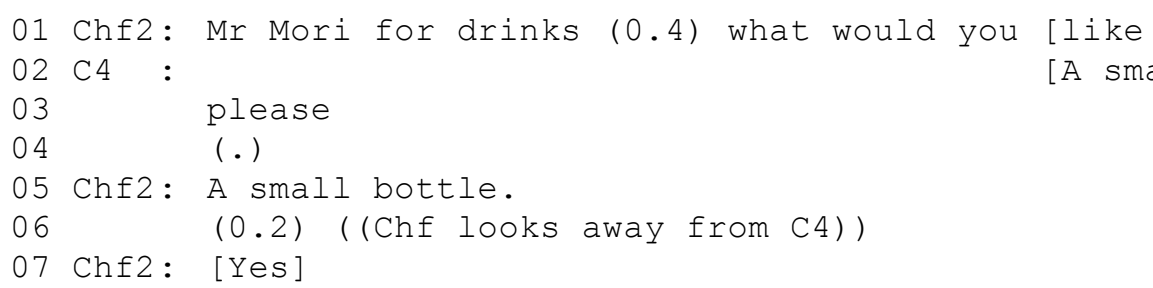


08 AS : [Yes]

((continues))

The chef addressed the customer by name (we have used a pseudonym), showing that this customer was a regular. The customer's order utterance (line 02) was not only succinct (without fillers, prolonged sounds, or an explicit rationale) but also heard as a knowledgeable response. Compare this fragment with Fragments 1-4, where it was necessary to discuss which size bottle to choose. In various service settings, many instances of such 'extended' order sequences can be found (Lee, 2009). In Fragments 1-4, these were extended in a sense that once 'beer' was chosen, a next question was needed regarding the size. However, in Fragment 8 the customer omitted the 'extended' sequence by ordering the final item as if he were already answering the possible next question. In this manner, the speaker demonstrated his status as a regular customer.

\section{First Food Orders}

We started with initial drink orders, the first occasion where customers' understandings of the routines are exhibited, and showed how routines are exhibited in the composition and placement of certain actions, i.e., questions. We now extend this analysis to the initial food order following the drink orders. Ordering drinks is difficult, but many customers were still able to pick beer, which is the standard alcoholic beverage in Japanese culture. Ordering food can be much more problematic, as we will see next.

Chefs typically ask customers, 'Can I cut something for you' (line 01 in Fragment 9). Although this question is a Yes/No interrogative in its literal sense, analysis shows that it requires specific items for the answers. This is made clear in Fragment 9 when a customer orders whitefish in response to the question (line 26).

\section{Fragment 9}

((Chf approaches to B2, looking at his face))

01 Chf : Can I cut something for you

$02(6.0)$ ((B2 looks at the glass case))

((22 lines omitted: B2 looks at the glass case where the prepared fish

blocks are displayed. While other customers are chatting during these

lines, there is no direct interaction between B2 and the chef.))

25 (5.3)( (Chf approaches a pail, but suddenly looks back and watches B2) )

26 B2 : All right then could you cut a little whitefish,

$27 \quad(0.4)$

28 Chf : Er: :

29 B2 : P [ l e a s]e?

30 Chf : $[$ A <whi>tefishi]

$31 \quad($.

32 Chf : Whit [efishi]

33 B2 : [Y $e \mathrm{~S}]$ 
When the chef asked the question about the first food order (line 01), the customer did not say anything and instead looked at the glass case where the prepared fish blocks were displayed as shown in Figure 4 (because the line drawing is not as clear as the video data, the direction of the gaze is indicated by an arrow). Therefore, we can conclude that the customer exhibited his understanding that he would need to pick a specific item to be cut in response to the seemingly Yes/No question. This is confirmed in that the chef acknowledged the customer understood the need to respond with a selection; the chef waited for this customer without starting to list possible items to choose from, which he did in the other cases. After 37 seconds the customer suddenly indicates a specific item 'whitefish' (line 26). In fact, this customer was one of the most experienced in this study; he frequents high-end sushi bars about 130 times a year. In this excerpt, the customer accepts the chef's definition of the routine and therefore can behave as a competent customer in this context.

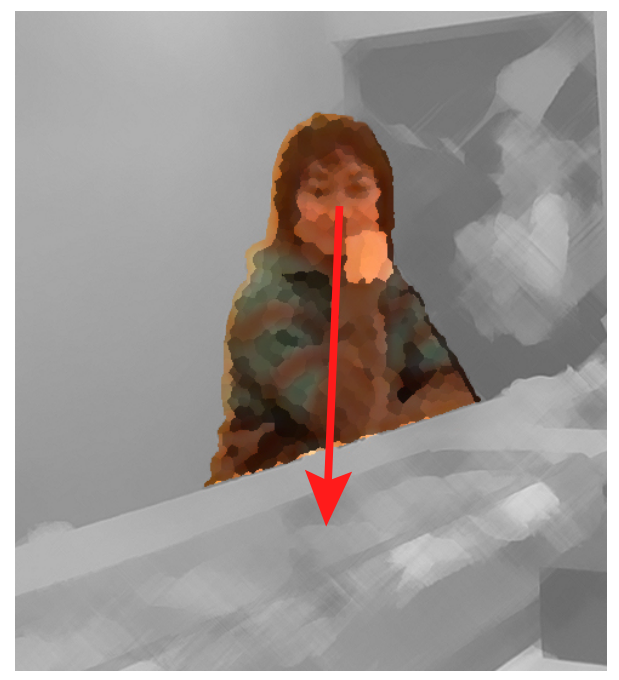

Figure 4: A customer looking at the glass case

The above analysis can be confirmed when we look at most instances in which customers respond to the first order question with 'Yes.'

\section{Fragment 10}

01 Chf : =otsumami(0.3) Shall I cut a little $\dot{c}=$

$02 \mathrm{Bla}:=(\mathrm{Ye}) \mathrm{s}$ could you start with otsu[mami]

03 Chf : 


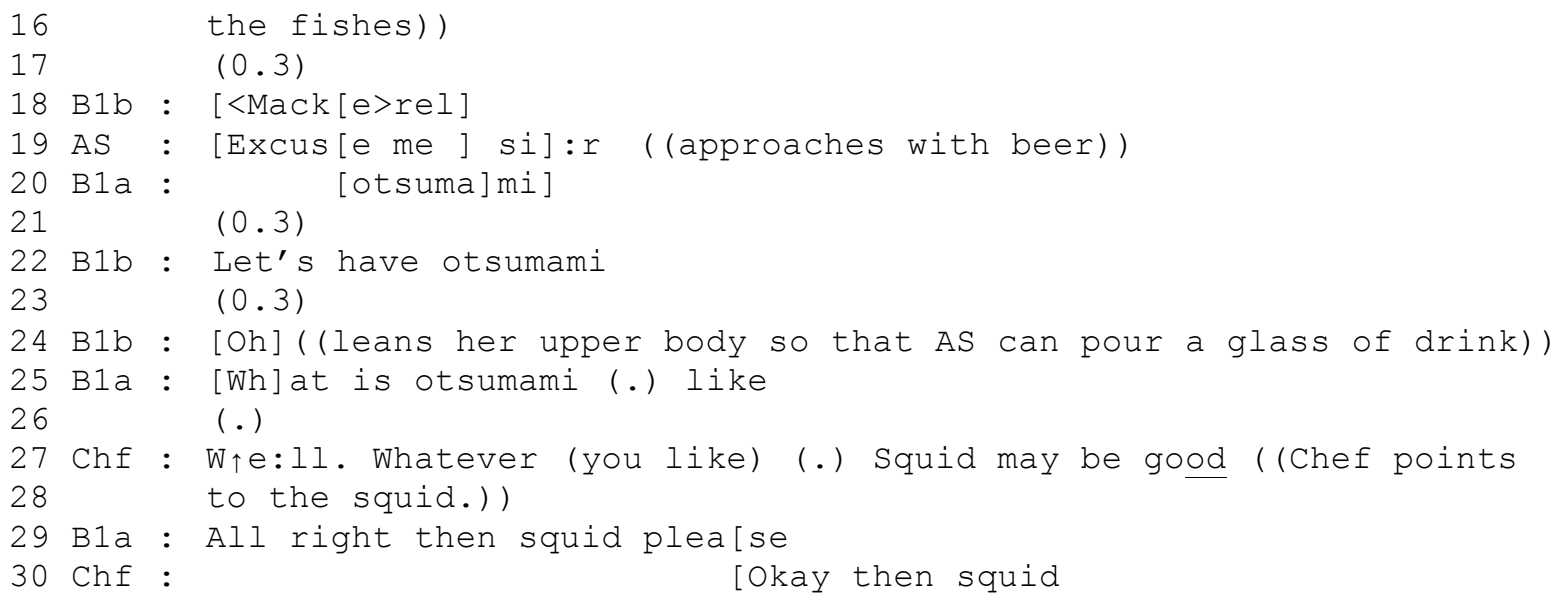

The chef asked a similar question in line 01 as he did in the previous interaction. The customer then answered, 'Yes,' in line 02. This customer exhibits his understanding that he completed the ordering sequence because he moved on to a new topic to discuss with his companion, i.e., photos. Note that he was given many opportunities, e.g., a 3.5 second pause in line 04 , to indicate his choice of fish or at least his intention to choose one. Therefore, this customer exhibited his understanding that his 'Yes' should be enough. However, the chef continued and asked 'What do you like' in line 09. The customer did not understand this question, either, and eventually asked, 'What is otsumami like' in line 25. 'Otsumami' is food to go with alcohol (typically in a restaurant it would be a type of appetizer). It is evident in the way he used the word 'otsumami' that the customer knew the literal meaning of the word 'otsumami'. However, he failed to understand what chef was doing by saying "Shall I cut a little $i$ ”. That is, the customer had a different idea of otsumami to that presented by the chef. Because the chef's question is understandable as defining a routine in this context, it is observable that the customer failed not only to understand the chef's question but also to understand the routine that the chef's action presented, i.e., what is expected as a routine interaction.

The following fragment shows a similar sequence.

\section{Fragment 11}

01 Chf : For y(ou) (0.3) Can I cut something?

$02 \quad(0.2)$

03 B3: Oh(0.2)yes. $(0.4)$ a little

$04 \quad(0.2)$

05 chf : What do you want to have.

$06 \quad(0.4)$

07 Chf : Well ((we have)) whitefish(0.2) raw sq<uid>.

$08 \quad(1.1)$

09 B3 : We:ll then $\left(\left(I^{\prime} l l\right)\right)$ start with white fish

10 Chf : Yes. 
The customer answered, 'yes,' to the chef's question in line 03. He then added, 'a little,' and completed the turn while at this position, he could have shown that he was thinking about what item to pick. Therefore, once again the customer exhibited that he believed 'Yes' was a sufficient answer to the chef's question. Then, the chef asked, 'What do you want to have,' in line 05. By issuing a question in response to the answer, the chef is, in effect, repeating the question and indicating that the customer's answer was not sufficient to complete the order. The customer could not answer this revised question, either. The 0.4 second pause in line 06 is long enough for the chef to know that the customer had trouble answering the question, and the chef gave further suggestions in line 07 . Only then could the customer complete his order.

Only a few experienced customers would know that, although the chef's initial utterance was a Yes/No question, neither of these short responses would be expected. Most customers would think that it is enough to simply answer yes. However, even if one learns that the response entails more than a simple Yes or No, it is not easy to pick what fish should be cut unless one is experienced in this type of interaction. Again, no written menu is provided, and one needs to know which fish would be good in a particular season. In the following case, this difficulty in picking a fish becomes salient, as here the customers had already ordered one dish and the chef asked whether he should cut something before the dish was ready.

\section{Fragment 12}

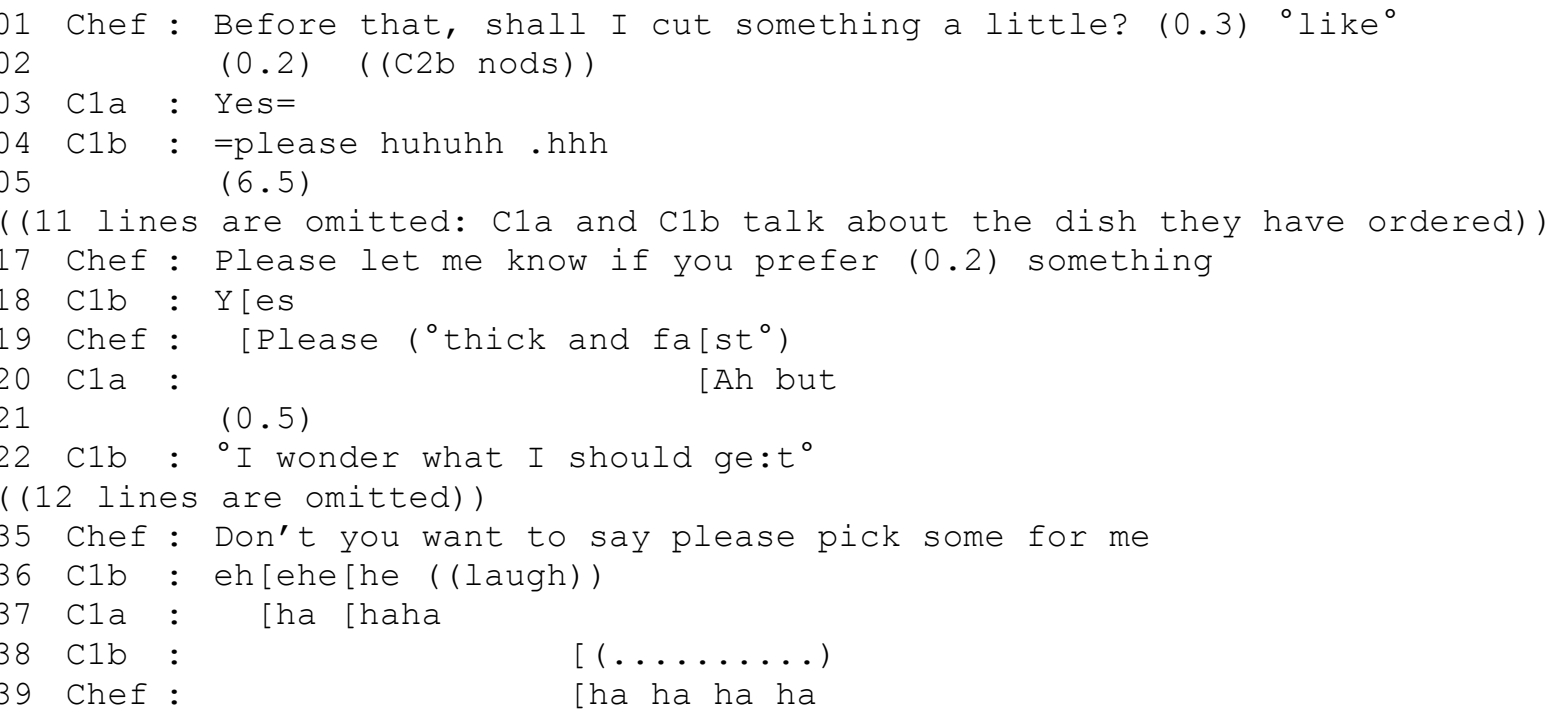

Here again the customer answered 'Yes' and another customer added, "please." They exhibited their understanding that they completed the order at this moment; they could have behaved differently in line 04 and during the subsequent 6.5 second pause in line 05 . The chef leaves and comes back to ask for an order again in line 17. At this moment, the customers understood that they needed to pick a specific fish, as is seen when they 
start wondering what they should get in line 22. Nonetheless, they could not do so for a while. After the customers took some time in making their choice of fish, the chef acknowledges the difficulty of ordering in line 35: The chef says, 'Don't you want to say please pick some for me.' This was presented as a joke, and the two customers and the chef all laughed. This utterance shows that it is breach of etiquette for customers to request that the chef 'please pick some for me'; customers need to select the proper fish. That is to say, the chef knew that it was a difficult question; however, he still repeated this question a few times until it became clear that the customers would not be able to make the choice. It is likely that due to his awareness of being filmed, the chef probably repeated the question without helping the customers with hints. Nonetheless, this shows his understanding that this process was the normative way to organize the ordering sequence. After this, the chef explained typical patterns that customers use.

In summary, the chefs' questions for food orders were composed concisely and asked as a matter-of-fact, i.e., routinely. Through these questions, the chefs exhibited their understanding of the routine and their expectations that the customers should be able to answer the questions without further information. Unlike drink orders, where customers often exhibited uncertainty in their behavior, in the case of food orders, customers tended to answer the question without much trouble. Yet, the chefs' actions following these utterances indicate that the answers were incomplete. Therefore, the chefs' and customers' understandings of the routine differed. They observed the difference and organized their actions; e.g., through the revision and elaboration of the questions by the chefs.

It is worth adding that all these analyses were based on how actions were presented to each other, and not the possible thoughts or intentions of the participants. Understandings of a routine were exhibited in actions. In most cases, people did not even explain their routines; they simply performed them. Only rarely did we observe an explicit explanation, e.g., the chef's overt remark in Fragment 12. Furthermore, the difference in understanding was also exhibited in actions. There was no need to reconcile or align the understandings prior to routine performance. In fact, we did not need to draw on shared agreements or schemas for the routine in order to describe how these routines were achieved. Within the performance, people rendered their actions accountable as part of a particular routine and thereby exhibited their own understanding of the routine. Understandings of a routine were presented and negotiated within the routine performance. 


\section{Discussion}

\section{Reflexivity of Routines}

This study addresses the question, how a routine is achieved despite different understandings of the routine. Particularly in high-end services, routines are often not obvious to customers; customers need to perform the routines without fully understanding them. Although theorists have touched on multiple understandings of a routine and the power struggles to negotiate among these understandings (Dionysiou \& Tsoukas, 2013; Feldman \& Pentland, 2003), how the understandings are presented and negotiated within, rather than from outside, the routine performance still requires more detailed explication. To this end, we paid attention to the reflexive relationship between the ostensive understandings and the performative actions.

We saw the service providers asked questions that were difficult for the customers. By asking these difficult questions as a matter of fact, the providers presented their understanding of the routine: Their customers should be sufficiently experienced to answer the questions without any further explanation. In this way, service providers could define their services as something valuable for customers who lacked extensive experience in sushi culture. Subsequently, we saw many customers did not respond to the questions in a fully mundane manner. They were oriented to the appropriateness of their actions. Some did not understand the routines or performed them in a way that the providers did not expect.

Therefore, we can see the sequential process by which a participant presents his or her own understanding of the routine and another participant acknowledges that understanding and presents his or her own understanding of the routine. In some cases, we observed that customers exhibited difficulty in answering questions. We showed this by describing such subtle cues as prolonged sounds and presentations of rationales for customer choices. Sometimes, the customers asked further questions to understand what the providers meant or answered questions in a way that the providers would indicate was unexpected, e.g., answering 'Yes' while the chefs sought a specific item in response. On the other hand, the providers tried to render the possibly disruptive interaction into an unproblematic routine. The providers often elaborated on their questions by listing possible choices and revising the questions in ways that customers would understand. In some cases, providers made the different understandings explicit by jokingly alluding to the difficulty the customers were facing. Through this sequential process of mutual presentation, participants can sense the difference in understandings, adjust their actions and achieve performance of the routine. The routine is achieved not because participants share the same schemata of the routine, but because at each moment they observe differences in understandings 
and take subsequent actions accordingly to render the interaction routine. Ostensive understandings are constructed and presented through performative actions.

Moreover, the analysis revealed that participants presented, observed, and responded to different understandings of a routine in a natural, matter-of-course manner. Providers asked initial questions as a matter of fact, as if these questions had been simply nothing more than a routine. We saw that providers understood customers could have difficulty in understanding these questions. In most cases, customers then also tried to respond to the questions in a routine manner. Therefore, the ostensive understanding is doubly performative: The understanding of a routine is presented through performance and at the same time, this presentation is performed routinely. To define a particular understanding of a routine, one does not need to explicitly state it; one simply performs the definition. Different understandings of a routine do not necessarily disrupt the routine performance; the difference can be performed in a routine manner.

Although there have been several ethnomethodological studies on customer interactions (Clark \& Pinch, 2010; Llewellyn \& Hindmarsh, 2013; Moore et al., 2010; Mortensen \& Hazel, 2014; Pinch \& Clark, 1986), how participants present and use different understandings of a routine still requires further explanation. The prior studies tend to focus on practical methods for aligning participants' understandings so that interactions can be achieved smoothly. In contrast, by examining sushi bars as a specific example of high-end service, this study has shown that participants presented and used the differences in performing the routines. In this sense, analysis of the data indicates that differences in understanding of a routine are an inherent part of the routine. Routine does not emerge only when the differences in understandings of the routine are minimized or sustained; routines can contain these differences as a key characteristic. Participants themselves are oriented to the differences and use them to define and organize the routine. The differences in understandings are not outside the routine performance but a reflexive part of it.

We do not claim that all customer interactions are organized in this manner. Some services, e.g., fast food, seem to be systematized to avoid challenging customers and make understanding of a routine as transparent to the customers as possible. Yet, this variety in service routines has yet to be empirically investigated. Any routine performance, no matter how smooth it appears, could engender multiple understandings of the routine and therefore should have a reflexive ability to handle these multiple understandings. Empirical research into reflexivity of routines will be needed to gain a more comprehensive understanding of routine performativity. 


\section{Refining Routine Theory}

Reflexivity is critical for the theory of routine. Feldman and Pentland (2003) discussed the fact that among participants there exist different ostensive understandings that need to be reconciled. Yet, how a particular ostensive understanding among them guides, accounts for, or refers to performative actions and how specifically this understanding is brought to bear on the performative actions has not been fully explained. If we assume that the understanding is reconciled before or after the routine performance, we need to admit that the performative actions must rely on an externally constructed ostensive understanding to be organized as a routine; that is, the performative actions are simply execution of what has been defined elsewhere.

We hope to answer these questions and offer some clarification to the existing theory. In order for performative actions to be organized as a routine, we do not need to assume that multiple understandings of a routine are reconciled into a single idea that can guide, account for, or refer to the performative actions. In the current study, providers and customers had different ideas about the routine. Participants reflexively used these different ideas. Providers in fact exhibited that their understandings of a routine were different from those of the customers and vice versa; only on rare occasions, did a chef even mention the difficulty he imposed on the customers, or did some customers touch on any problems they faced in understanding chefs' questions. This reflexive use of different understandings allowed performative actions to be organized as routines without the need to reconcile these different accounts into a coherent single account before the performance. Nor was it necessary to retrospectively construct a single understanding in order to frame the performance as a routine. Therefore, we can see that different understandings are presented, observed, and used within a routine performance.

We agree with Dionysiou and Tsoukas (2013) that participants have shared schemata only to the extent that they rely on a variety of commonsense knowledge. However, we need to add that these shared schemata alone do not ensure routine performance because it still remains unclear how participants can achieve routine interactions when each action could present a different understanding of the routine. Understandings of a routine may diverge within the routine performance while the notion of shared schemata assumes that participants already have compatible understandings. The above analysis revealed that divergent understandings can be reflexively handled without the need for a priori shared schemata.

Zbaracki and Bergen (2010) suggest that in routine performance different understandings are sustained under truce such that no negotiation is necessary and that negotiations take place when interactions are disrupted and become non-routine. Adding to this, we suggest that each routine performance can also contain negotiations 
among different understandings of the routine without the need to rely on non-routine negotiations. This negotiation is inevitable because there is no a priori reason to assume that participants have the same understanding; this negotiation must be done within each routine performance.

In the present study our empirical analysis showed that in actual interactions, there is no abstract and subjective ostensive idea that guides, accounts for, or refers to the situated performance. If such ostensive idea is relevant, it is always presented to others in a concrete manner. In other words, the ostensive aspect is not a subjective but an inter-subjective level construct. It does not matter what participants in a particular situation have in mind subjectively because what is in somebody's mind is not accessible to others in that situation. What matters is how an action is presented to others at an inter-subjective level. If we build the theory of routine on top of subjective constructs, we face a difficulty as to how to reconcile among independent subjective ideas that vary among participants. If there are possibly multiple ostensive understandings, it is only through performance that these multiple understandings are presented, observed, and used.

The concept of routine underpins theories of organization. The attraction of this concept of routine lies in the fact that routine is an inter-subjective level concept and can be used to explain inter-subjective phenomena like organizations. Yet, such inter-subjective concept of routine is often misconceived as abstract, mechanical processes free from individuals' subjective intentions. Routines end up being treated as static, automatic, and abstract. The performative view of routines tries to overcome this static view by using performativity as a more appropriate inter-subjective basis for the routine. Performativity is inter-subjective because performance is always public: Individuals need to present their own understanding of the performance. Nonetheless, if we treat the ostensive ideas as subjective, not inter-subjective, we insert a different problem to this framework: It is difficult to explain the inter-subjective concept of routine based on a subjective concept. Ostensive ideas are always performed at the inter-subjective level, rather than being abstract and general. Only in this context can we explain routines as an inter-subjective concept and properly base any theory of organizations on the concept of routines.

\section{What is Routine?}

Reflexivity further offers a clue as to how to define a routine. We need to base the definition of a routine not on researchers' accounts of a routine but on participants' own accounts. However, in actual routine performance, there can be multiple definitions of a routine. Therefore, we must re-examine Feldman and Pentland's (2003) definition of a routine: “a repetitive, recognizable pattern of interdependent actions involving multiple people." The issue is how a pattern of actions can be recognizable when multiple people exhibit 
multiple understandings of the same routine. If we stress reflexivity, we need to conclude that this definition of routine is also a reflexive part of the performative actions. That is to say, the definition of routine is an achievement of the performative actions rather than their precondition.

At each moment, participants themselves presented and observed their definitions of the routine. Therefore, while we can accept Feldman and Pentland's definition of a routine, we need to add that a pattern of interdependent actions are 'made recognizable' at each moment in this process by means of performative actions. That is to say, participants make each action accountable as part of a routine. There is no need to rely on an abstract ostensive concept about a routine that has been constructed elsewhere and then imported to a particular situation. The definitions of a routine are performed; and this performance is reflexively presented and observed as part of a routine.

Therefore, in cases when customers showed that they could not understand the chefs' definition of a routine and could not perform the routine as the chefs expected, it would be an arbitrary decision on our part as to whether this was a disruption of the routine or part of it. We could say that the routine was disrupted because the interaction did not unfold in the manner the chefs had projected. Alternatively we could say that this type of interaction was part of the routine because the customers could conclude ordering without complete breakdown. Instead of defining a routine from an external researchers' point of view, we can examine how participants themselves present and use their own definitions of the routine. Sometimes, the definitions diverged, but the participants recognized the divergence and adjusted their definitions.

Participants' own definitions of a routine are critical because in actual situations involving routines, participants try to define the routine in a specific way. In high-end service settings, service providers define the routine as something beyond what most customers have experienced and thereby as valuable. The difference in the definition was also important for customers; to present their own competence as being qualified customers, they perform the routine without demonstrating that they have different understandings from that of the chef. Therefore, participants in fact use divergent definitions. As a result, routine theory should view routines as a field of struggle to define the routine and thereby define the situation. Definition of a routine is performed within the routine.

Feldman and Pentland (2003) drew on Latour's (1986) notions of ostensive and performative definitions to develop their theory. Critical of the notion of an ostensive definition, Latour proposed performative definitions not in conjunction with but instead of ostensive definitions: 'We have to shift from an ostensive to a performative definition of society' (p. 272). Ethnomethodology offered a basis for this move. Nonetheless, 
Feldman and Pentland chose to retain the notion of an ostensive aspect and explored the relationships between the ostensive and performative aspects of routines. Latour wrote, 'Society is not the referent of an ostensive definition discovered by social scientists despite the ignorance of their informants. Rather, it is performed through everyone's efforts to define it' (p. 273). In the empirical analysis, we have seen that participants themselves performed the routine to define it. Participants then used the definitions that they each presented and organized the routine performance. Ostensive definitions, if they are observed, are not what researchers discover or impose but what participants themselves present within their performance.

\section{Conclusion}

This study contributes to research on routines by refining the theory of routine advanced by Feldman and Pentland (2003) and Dionysiou and Tsoukas (2013). The focus here was on how participants present different understandings of a routine but still achieve the interaction as a routine. Analysis revealed that participants presented their own understandings of a routine, which varied among participants, but understood each other's understandings and organized subsequent actions according to that understanding. This reflexive mechanism explains how service providers present a definition of a routine that is not necessarily familiar to customers in the routine interaction. The reflexivity in these interactions allows us to understand how a routine can be achieved without a single coherent understanding.

However, several questions remain. We focused on high-end services because this setting provided a valuable opportunity to observe divergent understandings of routines. This reflexive definition allows us to discuss, beyond the high-end service setting, a variety of routines in which not all participants share the same understanding. Feldman and Pentland's (2003) example of academic hiring, or any hiring (Llewellyn \& Spence, 2009), is relevant in this context. Llewellyn and Spence (2009) showed that interviewers regularly evaluated candidates by posing difficult questions and keeping the candidates struggling for periods of time, and that candidates sometimes used ingenious methods to present their competence. Therefore, we should be able to observe similar reflexivity in other routines, particularly routines at organizational boundaries, which are interesting in this regard because persons not known to the organization are often involved. Customer interaction is particularly salient in this category. 


\section{Appendix: Transcription System}

\begin{tabular}{|l|l|}
\hline Symbols & Description \\
\hline[ & Point of overlap onset \\
\hline$]$ & Point of overlap outset \\
\hline$=$ & Connecting two lines represent no discernible silence between the lines \\
\hline$(1.2)$ & Pause in seconds. \\
\hline$()$. & Hearable but not readily measurable short silence (less than $0.2 \mathrm{sec})$ \\
\hline$\cdot$ & Falling intonation contour, not necessarily the end of a sentence \\
\hline, & Low rising intonation contour, not necessarily a clause boundary \\
\hline$i$ & Mid rising intonation contour \\
\hline$?$ & High rising intonation contour \\
\hline$:$ & Stretched voice \\
\hline$\underline{\text { Word }}$ & Stressed talk \\
\hline o o & Relatively quieter voice \\
\hline- & A hyphen denotes a cut-off \\
\hline$><$ & Relatively rushed or compressed talk \\
\hline$<$ & Markedly slow talk \\
\hline$($ word $)$ & Parentheses around a word or a phrase denote the transcriber's guess at what might be said. \\
\hline$\uparrow$ & Rising intonation shift \\
\hline H & Exhaling \\
\hline. $\mathrm{h}$ & Inhaling \\
\hline \#word\# & Smiley voice \\
\hline
\end{tabular}

\section{References}

Becker, M. C. (2005). The concept of routines: some clarifications. Cambridge Journal of Economics, 29(2), 249-262.

Clark, C., \& Pinch, T. (2010). Some major organisational consequences of some "minor," organised conduct: evidence from a video analysis of pre-verbal service encounters in a showroom retail store. In N. Llewellyn \& J. Hindmarsh, Organisation, interaction and practice (pp. 140-171). Cambridge: Cambridge University Press.

Cohen, M. D. (2007). Reading Dewey: Reflections on the study of routine. Organization Studies, 28(5), 773786.

Corson, T. (2009). The story of sushi. New York: HarperCollins.

Dionysiou, D. D., \& Tsoukas, H. (2013). Understanding the (re)creation of routines from within: A symbolic interactionist perspective. Academy of Management Review, 38(2), 181-205.

Feldman, M. (2000). Organizational routines as a source of continuous change. Organization Science, 11(6), 611-629.

Feldman, M., \& Pentland, B. (2003). Reconceptualizing organizational routines as a source of flexibility and change, 48(1), 94-118.

Garfinkel, H. (1967). Studies in Ethnomethodology. Cambridge, UK: Polity.

Gherardi, S., \& Nicolini, D. (2002). Learning in a constellation of interconnected practices: canon or dissonance? Journal of Management Studies, 39(4), 419-436.

Hindmarsh, J., \& Pilnick, A. (2007). Knowing bodies at work: Embodiment and ephemeral teamwork in anaesthesia. Organization Studies, 28(9), 1395-1416.

Hodgson, G. M. (2008). The concept of a routine. In M. C. Becker, Handbook of organizational routines (pp. 15-28). Cheltenham, UK: Edward Elgar Publishing.

Hodgson, G. M. (2013). Understanding organizational evolution: Toward a research agenda using generalized Darwinism. Organization Studies, 34(7), 973-992.

Knudsen, T. (2008). Organizational routines in evolutionary theory. In M. C. Becker, Handbook of organizational routines (pp. 125-151). Cheltenham, UK: Edward Elgar Publishing.

Kuroshima, S. (2010). Another look at the service encounter: Progressivity, intersubjectivity, and trust in a Japanese sushi restaurant. Journal of Pragmatics, 42(3), 856-869.

Latour, B. (1986). The powers of association. The Sociological Review, 32, 264-280. 
Lee, S.-H. (2009). Extended requesting: Interaction and collaboration in the production and specification of requests. Journal of Pragmatics, 41(6), 1248-1271.

Llewellyn, N. (2008). Organization in actual episodes of work: Harvey Sacks and organization studies. Organization Studies, 29(05), 763-791.

Llewellyn, N., \& Hindmarsh, J. (2010). Organisation, Interaction and Practice. Cambridge: Cambridge University Press.

Llewellyn, N., \& Hindmarsh, J. (2013). The order problem: Inference and interaction in interactive service work. Human Relations, 66(11), 1401-1426.

Llewellyn, N., \& Spence, L. (2009). Practice as a members' phenomenon. Organization Studies, 30(12), 14191439.

Miettinen, R., Samra-Fredericks, D., \& Yanow, D. (2010). Re-turn to practice: An introductory essay. Organization Studies, 30(12), 1309-1327.

Moore, R. J., Whalen, J., \& Gathman, E. C. H. (2010). The work of the work order: document practice in faceto-face service encounters. In N. Llewellyn \& J. Hindmarsh, Organisation, interaction and practice (pp. 172-197). Cambridge: Cambridge University Press.

Mortensen, K., \& Hazel, S. (2014). Moving into interaction-Social practices for initiating encounters at a help desk. Journal of Pragmatics, 62, 46-67.

Nelson, R. R., \& Winter, S. G. (1985). An Evolutionary Theory of Economic Change. Cambridge, MA: Belknap Press of Harvard University Press.

Pentland, B. T., \& Feldman, M. S. (2007). Narrative networks: Patterns of technology and organization. Organization Science, 18(5), 781-795.

Pentland, B. T., \& Feldman, M. S. (2008). Designing routines: On the folly of designing artifacts, while hoping for patterns of action. Information and Organization, 18(4), 235-250.

Pentland, B. T., Feldman, M. S., Becker, M. C., \& Liu, P. (2012). Dynamics of organizational routines: A generative model. Journal of Management Studies, 49(8), 1484-1508.

Pentland, B. T., Haerem, T., \& Hillison, D. (2011). The (n)ever-changing world: Stability and change in organizational routines. Organization Science, 22(6), 1369-1383.

Pinch, T., \& Clark, C. (1986). The hard sell: "patter merchanting" and the strategic (re)production and local management of economic reasoning in the sales routines of market pitchers. Sociology, 20(2), 169-191.

Schegloff, E. A. (2007). Sequence Organization in Interaction: Volume 1: A Primer in Conversation Analysis (1st ed.). New York: Cambridge University Press.

Suchman, L. A. (2007). Human-machine reconfigurations. Cambridge: Cambridge University Press.

Tsoukas, H., \& Chia, R. (2002). On organizational becoming: Rethinking organizational change. Organization Science, 13(5), 567-582.

Turner, S. F., \& Rindova, V. (2012). A Balancing act: How organizations pursue consistency in routine functioning in the face of ongoing change. Organization Science, 23(1), 24-46.

Zbaracki, M. J., \& Bergen, M. (2010). When truces collapse: A longitudinal study of price-adjustment routines. Organization Science, 21(5), 955-972. 
Table 1: Study participants

\begin{tabular}{|l|l|l|l|}
\hline \multicolumn{1}{|c|}{ Participants $^{1}$} & $\begin{array}{c}\text { Labels used in } \\
\text { transcripts }^{2}\end{array}$ & Sushi bar & Number of visits to sushi bars per \\
\hline 1 & A1a & A & 10 \\
\hline 2 & A1b & A & 2 to 3 \\
\hline 3 & A2a & A & 1 \\
\hline 4 & A2b & A & 1 \\
\hline 5 & A3a, B4a, C5 & A, B, C & 6 \\
\hline 6 & A3b, B4b & A, B & 2 to 3 \\
\hline 7 & A4, B3 & A, B & 20 to 30 \\
\hline 8 & A5 & A & 0 \\
\hline 9 & A6a & A & 1 \\
\hline 10 & A6b & A & 1 \\
\hline 11 & A6c & A & 0 \\
\hline 12 & B1a & B & 5 \\
\hline 13 & B1b & B & 3 \\
\hline 14 & B2 & B & 130 \\
\hline 15 & C1a & C & 4 \\
\hline 16 & C1b & C & 3 \\
\hline 17 & C2a & C & 6 \\
\hline 18 & C2b & C & 5 \\
\hline 19 & C3 & C & 20 \\
\hline 20 & C4 & C & 200 \\
\hline 1 & A few participants took part in multiple studies. The same number is given to them. \\
2 & Individuals in a group are indicated with subscripts a, b and c. \\
\hline
\end{tabular}

